Chapter 12

\title{
Techniques for the Evaluation of Microbiological Quality in Honey
}

\author{
Maria Josiane Sereia, \\ Marcia Regina Ferreira Geraldo Perdoncini, \\ Paulo Henrique Março, Rejane Stubs Parpinelli, \\ Erica Gomes de Lima and Fernando Antônio Anjo
}

Additional information is available at the end of the chapter

http://dx.doi.org/10.5772/67086

\begin{abstract}
The aim of this chapter is to describe the most commonly used techniques to evaluate the microbiological characteristics of honey for the purpose of identifying its contaminant flora, its significance and its control in this type of food. Honey is a product that is rich in simple sugars, minerals, vitamins and bioactive compounds and possesses an antimicrobial activity of great significance for human health. However, as it has physical and chemical properties that are unfavourable for the proliferation of micro-flora, honey can contain a large population of microorganisms from two sources of contamination-the first primarily represented by pollen, the digestive system of the bee, dust, air and the flower itself; and the second as the result of negligence and the absence of good health practices during handling and use; for example, placing honey in wooden beehives directly on the floor or the use of improperly washed honey extraction equipment, rather than equipment based on the oxidizable material, or using very dark honeycombs and storing the honey for long periods in wooden beehives. As honey is a natural product, the risks inherent to the lack of industrial processing, such as pasteurization and strict microbiological quality control, are often overlooked.
\end{abstract}

Keywords: microbiological analysis, microbiological standards, good habits, antimicrobial action, antimicrobial agents 


\section{Introduction}

Most of the analysis techniques described in this chapter were recommended by the Agência Nacional de Vigilância Sanitária (the National Health Surveillance Agency) (ANVISA) [1], including the Official Analytical Methods for the Microbiological Analysis and Control of Products from Animal and Water Sources [2], those of the American Public Health Association; described in the fourth edition of the Compendium of Methods for the Microbiological Examination of Foods [3-5], the International Commission on Microbiological Specifications for Foods [6, 7]; the Food and Drug Administration (FDA), recommended by the Ministry of Agriculture for the analysis of foods of animal origin, in accordance with Normative Instruction number 62, dated August 26th, 2003 [2]; the Food Safety and Inspection Service of the US Department of Agriculture [8], the Association of the Official Methods of Analysis of AOAC International [9], the Bacteriological Analytical Manual (FDA) [10], the Microbiology Laboratory Guidebook [11] and the latest editions of the International Organization for Standardization $[12,13]$.

Among the various parameters that indicate the quality and safety of honey, the most important are those that define its microbiological characteristics. Honey, as with any other raw material of vegetable or animal origin, naturally presents microbial contaminants of commercial importance formed by microorganisms adapted to the characteristics of the honey, such as high-sugar content, low acidity and the presence of natural antimicrobial substances. Because of these characteristics, the microbial load in honey is generally low, below $10^{2}$ $\mathrm{CFU} / \mathrm{g}$, and can even reach $10^{3}-10^{4} \mathrm{CFU} / \mathrm{g}$. Consequently, it can cause undesirable changes by reducing the shelf-life of the product. It presents floral indicators of the possible presence of pathogenic microorganisms, and so can be harmful to the health of the consumer. Protecting food products from any kind of contamination or adulteration which can cause harm to public health or economic disorder is a global concern [8] and specific methods of analysis are required to evaluate this type of raw material. Moreover, the risks represented by the poor handling conditions used by workers responsible for the harvest, extraction and preparation of this product require effective interventions and procedures to minimize these risks [14].

Aiming to control the quality of honey, the World Trade Organization recommends the adoption of standards, guidelines and norms developed by Codex Alimentarius - the revised codex standard for honey 2001 [15]. This is an international public agency created by the Food and Agricultural Organization (FAO) and the World Health Organization (WHO) [16], both of which form part of the United Nations Organization (UNO). MERCOSUL GMC resolution $\mathrm{n}^{\circ}$ 151994 approved the Technical Regulations for the Identity and Quality of Honey, based on resolutions $n^{\circ} 18$ (1992) and $n^{\circ} 91$ (1993) of the Common Market Group [17], in which honey can contain a maximum of 100 colony forming units of fungus per gram (CFU/g). Normative instruction $n^{\circ} 11$ approved, on 20 October 2000, the Technical Regulations for the Identity and Quality of Honey [18] and normative instruction $n^{\circ} 3$ dated January 19th 2001 approved the Technical Regulations for the Identity and Quality of bee apitoxin, beeswax, royal jelly, lyophilized royal jelly, bee pollen, propolis and propolis extract [19], as previously microbiological standards had not been established for these apiculture products. To ensure the 
credibility of the results however, some steps must be observed. The methods in this chapter are described as simply as possible in order to be accessible to fully qualified professionals, lab technicians and students with varying levels of education and training. This chapter provides comprehensive material presented in a didactic manner, with texts and diagrams that facilitate understanding. The basic techniques of microbiology described are accompanied by a brief overview of the microorganism researched in order to provide a solid theoretical basis, which will be of great value for understanding the method and interpretation of results. This chapter, therefore, aims to present the most commonly used techniques for assessing the microbiological characteristics of honey to identify its contaminant flora, its significance and its control in this type of food.

\subsection{Sampling plan for the microbiological analysis of honey lots}

Sampling plans allow the evaluation of the microbiological conditions of honey lots. These were proposed by the International Commission on Microbiological Specifications for Foods [6] and their application supports the acceptance or rejection of a honey lot as a whole, describing the hygienic sanitary conditions under which this food was obtained, processed, stored, distributed for consumption, as well as its shelf life and the risk posed to consumer health.

For the microbiological analysis of a honey lot, it is necessary to define some important concepts, such as: lot, $n, c, m$ and $M$. A 'lot' is the total units of honey pots produced, handled or stored under the same conditions, within a certain period; ' $n$ ' is the number of units taken randomly from a lot to be analysed individually. For honey, ' $n$ ' is equal to five sample units and constitutes a representative sample of the lot; ' $m$ ' is the set of microbiological standards established for a microorganism in a given food; ' $c$ ' is the maximum acceptable number of units in which microbial counts in the lot are above the minimum threshold $(m)$ and below the maximum tolerated limit $(M){ }^{\prime}{ }^{\prime}{ }^{\prime}$ is the tolerable limit, above standard, which can be reached by (c) sample units, but cannot be exceeded by either [6].

Brazilian legislation on the microbiological requirements of food includes Ordinance $n^{\circ} 101$ of 1993 of the Ministry of Agriculture, Livestock and Supply and RDC-12 Resolution 2001 of the National Health Surveillance Agency of the Ministry of Health [1]. In the case of honey (molasses and similar) a value of $n=5$ is adopted, while values of $c, m$ and vary according to the microorganism considered: coliforms at $45^{\circ} \mathrm{C} / \mathrm{g}\left(n=5, c=2, m=10\right.$ and $\left.M=10^{2}\right)$ and Salmonella $s p / 25 \mathrm{~g}(n=5 c=0 ; m=$ absent $)$ under this legislation are more flexible than the levels established by Mercosul [17] in which honey must meet the following microbiological characteristics: Coliforms at $35^{\circ} \mathrm{C} / \mathrm{g}(n=5, c=0, m=0)$; Salmonella spp - Shigella spp/25 g $(n=10, c=0$, $m=0)$; Fungi and Yeast CFU/g $(n=5, c=2 m=10, M=100)$. Therefore, a maximum of 100 colony forming units of fungus per gram of honey $(\mathrm{CFU} / \mathrm{g})$ is acceptable.

For the analysis of Salmonella sp/25 g, a two-class plan is applied, as this trial investigates the presence or absence of this microorganism. In this case, ' $c$ ' is equal to zero, absence is acceptable and the presence of any sample unit is unacceptable. In these tests a single sample analysis is performed. For analysis of coliform $45^{\circ} \mathrm{C}$, a three-class plan is applied, which classifies lots into three categories: acceptable, intermediate and unacceptable. In this case, the standard is 
not absence but values within a range between $m$ and $M$. In the two-class plan, $M$ separates acceptable from unacceptable lots. In a three-class plan this value separates an acceptable lot from an intermediate lot $[10,11]$.

\subsection{Transport of samples}

Samples of food concentrates such as honey are microbiologically stable and can be transported and stored at ambient temperature. Nevertheless, they should be protected against moisture and excessive heat [20].

\subsection{Analytical unit}

This is the amount of food sample used in conducting one or more tests. The sample unit must be greater than that required for analysis, with sufficient quantities for the counter-sample.

In Brazil, tests for the quantitation of microorganisms in honey comprise mould and yeast counts, the count of total and faecal coliforms and Salmonella analysis, the trials of which are usually done with an analytical unit of $25 \mathrm{~g}$ of honey (in special cases at least $10 \mathrm{~g}$ of honey can be used). Analytical units of $25 \mathrm{~g}$ meet the requirements of ISO 6887-1 [20], and those of the Compendium, for all tests. Two analytical units are required for analysis of a honey sampleone for mould and yeast quantification, total and thermotolerant coliform count and the other test for the absence or presence of Salmonella.

\subsection{Homogenization of the honey sample and withdrawal of the analytical unit}

Disinfect the area outside the packaging with $70 \%$ ethanol and remove the jar lid aseptically. Observe and note the presence of abnormalities in the packaging or in the internal content such as bloating, leakage, the presence of foreign bodies, odour and/or strange appearance.

Before the withdrawal of analytical units, the content of the sample should be homogenized to ensure that the removed portion is representative of all the material. In the case of honey in a jar with enough room for agitation, the package should be inverted 25 times. If there is no free space for agitation, use a second sterile vial and transfer the sample from one vial to another three times. Remove the analytical unit with a sterile spatula (ISO 6887-5: 2010) [21].

\section{Description of methods}

To increase the reliability of the results obtained, all tests should be performed in triplicate, following the methods described below.

\subsection{Total and thermotolerant coliforms}

The bacteria are in Gram-negative bacilli form, are facultative, not sporogenic anaerobes, capable of fermenting lactose with gas production, and are temperature dependent. Total coliforms, also known as coliforms at $35^{\circ} \mathrm{C}$, are a sub-group of the Enterobacteriaceae family. 
The second edition of Bergey's Manual of Systematic Bacteriology [22] includes 44 genera and 176 species in this sub-group. The total coliform group includes only enterobacteria that can ferment lactose with the production of gas, for $24-48$ hours at $35^{\circ} \mathrm{C}$. More than 20 species fall into this category, including bacteria originating from the gastrointestinal tract of humans and other warm blooded animals such as Escherichia coli, and non-enteric bacteria such as Citrobacter, Enterobacter, Klebsiella and Serratia, among others [23].

Lactose fermentation capacity is analysed through the formation of gas and/or acid in the lactose-containing culture media. These characteristics are used in traditional methods of total coliform counting.

With modern methods, it is possible to directly detect the activity of the $\beta$-galactosidase enzyme involved in the fermentative metabolism of lactose, incorporating the substrates for the enzyme in culture media. One of these substrates is ONPG (ortho-nitrophenyl- $\beta$-Dgalactopyranoside) which when degraded by $\beta$-galactosidase results in a product that is yellow in colour. It also possesses the X-GAL (5-bromo-4-chloro-3-indolyl- $\beta$-D-galactopyranoside) substrate, which results in a product with an intense blue staining, and Salmon-Gal (6-chloro3 -indolyl- $\beta$ - D-galactopyranoside), whose degradation product is a salmon red colour [23, 24].

The thermotolerant coliform group, also known as coliforms at $45^{\circ} \mathrm{C}$ but usually called faecal coliforms, is a subgroup of total coliforms which are restricted to members capable of fermenting lactose in 24 hours at $44.5-45.5^{\circ} \mathrm{C}$ with gas production [23-25]. While this definition aims in principle to select only enterobacteria that originate from the gastrointestinal tract (E. coli), it is currently known that the group includes members of non-faecal origin (various strains of Klebsiella pneumoniae, Pantoea agglomerans, Enterobacter aerogenes, Enterobacter cloacae and Citrobacter freundii) [23].

Escherichia coli have as their natural habitat the intestinal tract of warm-blooded animals, but can be introduced into food from non-faecal sources. They can grow in eosin methylene blue agar where their growth characteristics allow them to be distinguished from other coliforms [23, 25-27].

These bacteria by themselves do not generally represent a major risk, but can indicate poor quality food that may contain harmful agents. According to the International Commission on Microbiological Specifications for Foods [7], total coliforms, thermotolerant coliforms and Escherichia coli are microorganisms with a low or indirect risk to health. Their presence may indicate inadequate hygiene and sanitation, demonstrating failures during post-processing, as they are easily inactivated by sanitizers and heat treatment.

Method: This is based on the most probable number (MPN) technique involving inoculation in tubes with lauryl sulphate tryptose broth (LST). This technique is the most used for coliform-bacteria counting. The most probable number in a sample is determined by using a confidence interval table at $95 \%$ probability for the various positive tube combinations in three or five tube series $[27,28]$.

This method enables the density of the viable organisms present in a sample under analysis to be estimated and is based on the principle that the bacteria present in a sample can be separated by agitation, resulting in a suspension of bacterial cells, evenly distributed in the sample. 
It is based on the inoculation of an increasing sample volume in a suitable culture medium for the growth of microorganisms, with each volume being inoculated into a series of tubes. Inoculum is obtained by sampling successive dilutions, the streaking of which provides positive and/or negative results allowing the calculation of the density of bacteria investigated by the application of probability calculations.

According to the methods studied, total and thermotolerant coliform and E. coli counting by the most probable number method is conducted in four steps [5, 7, 9, 23, 26-28]:

(1) Presumptive test for total coliforms: using lauryl sulphate tryptose broth the observation of growth with gas production is considered suspect (presumptive) for the presence of coliforms. The presence of the surfactant in the lauryl sulphate tryptose broth inhibits the growth of the cytoplasmic membrane of Gram-positive bacteria and enables the presence of lactose fermentation, which releases carbon dioxide. The presence of this gas is evident in the Durham tube.

(2) Confirmation of total coliform test: using brilliant green bile broth (BGBB) there is notable development of bacteria of the coliform group, which is again confirmed by the formation of gas. This occurs because this broth is selective due to the presence of bovine bile and a triphenylmethane dye derivative which inhibits Gram-positive bacteria and sporulated lactose fermenting bacteria. This step of the examination reduces the possibility of false positive results arising from the activity of sporulated bacteria and Gram-positive lactose fermenting bacteria. Observation of growth through gas production in brilliant green bile tubes is considered confirmatory for the presence of total coliforms.

(3) Confirmation test for thermotolerant coliforms: this method uses Escherichia coli broth (EC) containing lactose, a selective medium containing a mixture of phosphate which maintains the $\mathrm{pH}$ of the medium at an appropriate amount. This selectivity is due to bile salts, which inhibit the growth of the Gram-positive microorganism. If there is gas formation in these conditions the thermotolerant coliform is confirmed [29]. The positive Escherichia coli tubes for thermotolerant coliforms are suspect for the presence of E. coli.

(4) Confirmation testing for E. coli: this method uses eosin methylene blue agar, which is a selective differential medium that distinguishes E. coli from other thermotolerant coliforms. If there is development of typical colonies of E. coli in this agar, these colonies are isolated for the biochemical proof of indole, methyl red, Voges-Proskauer and citrate (IMViC).

- Sample preparation: weigh $25 \mathrm{~g}$ of honey and add to $225 \mathrm{~mL}$ of peptone water $0.1 \%$ and homogenize the sample. This provides a $10^{-1}$ dilution; where $1 \mathrm{~mL}$ of the same corresponds to $0.1 \mathrm{~g}$ of the sample. A quantity of $1.0 \mathrm{~mL}$ of this solution $\left(10^{-1}\right)$ is transferred using a new sterile pipette to a $9.0 \mathrm{~mL}$ of dilution water, thus obtaining a second decimal dilution $\left(10^{-2}\right)$, where $1 \mathrm{~mL}$ corresponds to $0.01 \mathrm{~g}$ of the sample. In the same way, a $10^{-2}$ dilution provides a $10^{-3}$ solution (Figure 1).

- Presumptive Test: for presumptive evidence, $1 \mathrm{~mL}$ of the three subsequent dilutions should be inoculated in a series of three test tubes containing broth lauryl sulphate tryptose, with 
one series for each dilution. The tubes should be incubated at $35^{\circ} \mathrm{C}$ for $24-48$ hours. If after this time there is turbidity of the medium and the formation of gas in the Durham tube, the presumptive test is positive for the presence of coliforms and should be subjected to confirmatory tests. If there is no turbidity in the medium or gas formation during the incubation period, the analysis ends at this stage and the test result is negative.

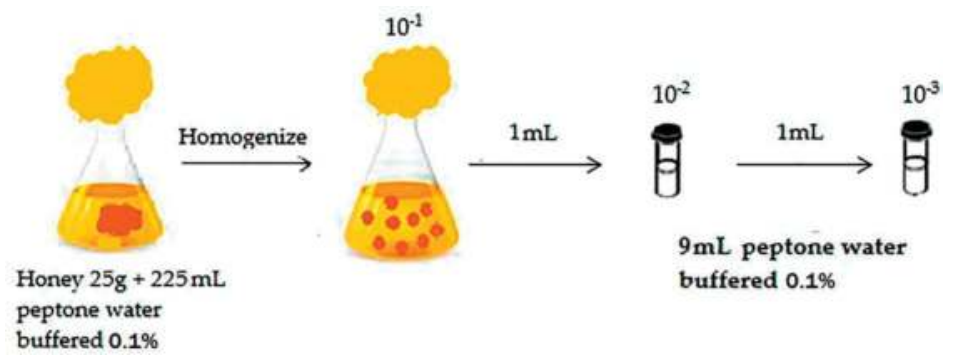

Figure 1. Decimal dilutions prepared $\left(10^{-1} ; 10^{-2}\right.$ and $\left.10^{-3}\right)$ from honey sample.

- Confirmation test of total and thermotolerant coliforms: to confirm the total coliform transfer, with a previously heated and cooled platinum inoculation loop, three loops from each positive tube and inoculate in a corresponding tube containing the bright green bile broth and incubate at $35^{\circ} \mathrm{C}$ for $24-48$ hours. At the same time, perform a confirmatory test for the coliforms, similarly transferring the same ratios to tubes of Escherichia coli broth and incubating at $44.5^{\circ} \mathrm{C}$ for $24-48$ hours. After this time, for the two tests, the formation of gas is observed in the Durham tube. If there is clouding of the medium and gas formation in the Durham tubes in the bright green bile broth the presence of total coliforms is confirmed, while the Escherichia coli broth confirms faecal coliforms. If there is no turbidity of the medium and no gas formation in the Durham pipes, the test is considered negative.

- Biochemical test to confirm E. coli: the tubes that present positive results for thermotolerant coliforms and/or tubes positive for coliform $35^{\circ} \mathrm{C}$ should be plated with a platinum loop with streaking on the surface of the Levine eosin methylene blue agar culture medium. The plates should be incubated at $35^{\circ} \mathrm{C}$ for 24 hours. Two colonies characteristics of E. coli (which are semi-nucleated with black centres and the presence or absence of metallic green brightness) must be isolated and subjected to biochemical tests of indole, methyl red, Voges-Proskauer and citrate [29]. The cultures with the profiles + + - (biotype 1) or - + - - (biotype 2) are considered confirmed (Figure 2).

Reading of test using most probable number (MPN): the most probable number technique is based on the statistical probability related to the frequency and occurrence of the most probable positive results in terms of the real number of microorganisms present. Three sets of three tubes are inoculated, employing dilutions $0.1 ; 0.01$ and $0.001 \mathrm{~mL} / \mathrm{g}$ of honey. Thus, the number of tubes per series of three consecutive dilutions is three, giving a total of nine tubes. The number of microorganisms in the original sample is determined using the most probable number tables (Tables 1 and 2), according to the Brazilian Association of Technical Standards [30]. 


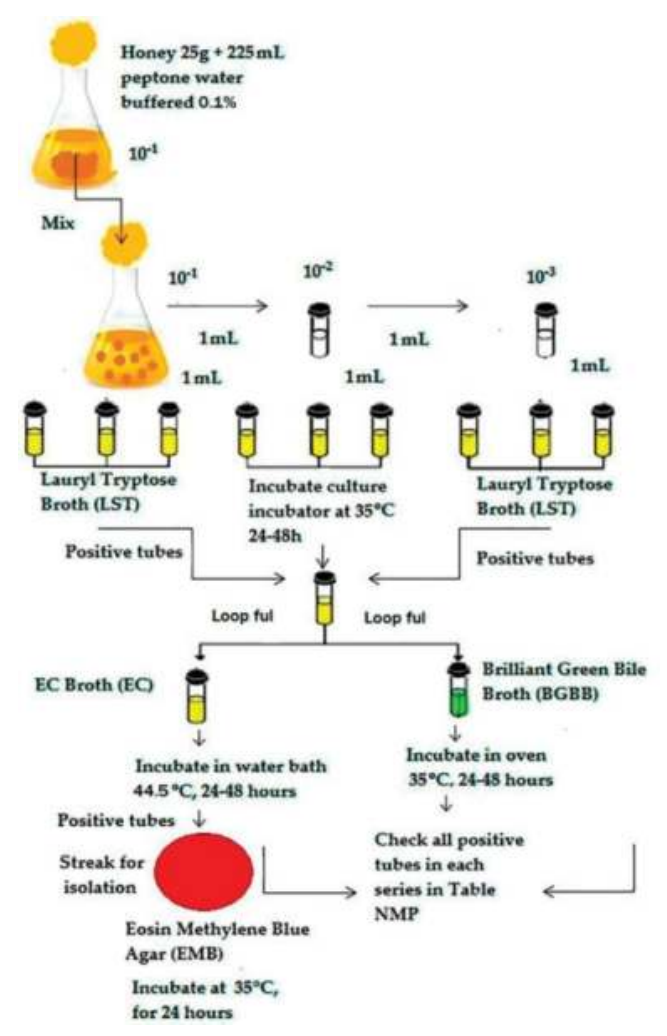

Figure 2. Presumptive and confirmatory tests of coliforms at 35 and $45^{\circ} \mathrm{C}$.

\begin{tabular}{|c|c|c|c|c|c|c|c|}
\hline \multicolumn{4}{|c|}{ Combination of positive tubes } & \multicolumn{4}{|c|}{ Combination of positive tubes } \\
\hline $0.1 \mathrm{~g}$ & $0.01 \mathrm{~g}$ & $0.001 \mathrm{~g}$ & MPN & $0.1 \mathrm{~g}$ & $0.01 \mathrm{~g}$ & $0.001 \mathrm{~g}$ & MPN \\
\hline 0 & 0 & 0 & $<3$ & 2 & 0 & 0 & 9.1 \\
\hline 0 & 0 & 1 & 3.0 & 2 & 0 & 1 & 14.0 \\
\hline 0 & 0 & 2 & 6.0 & 2 & 0 & 2 & 20.0 \\
\hline 0 & 0 & 3 & 9.0 & 2 & 0 & 3 & 26.0 \\
\hline 0 & 1 & 0 & 3.0 & 2 & 1 & 0 & 15.0 \\
\hline 0 & 1 & 1 & 6.1 & 2 & 1 & 1 & 20.0 \\
\hline 0 & 1 & 2 & 9.2 & 2 & 1 & 2 & 27.0 \\
\hline 0 & 1 & 3 & 12.0 & 2 & 1 & 3 & 34.0 \\
\hline 0 & 2 & 0 & 6.2 & 2 & 2 & 0 & 21.0 \\
\hline 0 & 2 & 1 & 9.3 & 2 & 2 & 1 & 28.0 \\
\hline
\end{tabular}




\begin{tabular}{|c|c|c|c|c|c|c|c|}
\hline \multicolumn{4}{|c|}{ Combination of positive tubes } & \multicolumn{4}{|c|}{ Combination of positive tubes } \\
\hline $0.1 \mathrm{~g}$ & $0.01 \mathrm{~g}$ & $0.001 \mathrm{~g}$ & MPN & $0.1 \mathrm{~g}$ & $0.01 \mathrm{~g}$ & $0.001 \mathrm{~g}$ & MPN \\
\hline 0 & 2 & 2 & 12.0 & 2 & 2 & 2 & 35.0 \\
\hline 0 & 2 & 3 & 16.0 & 2 & 2 & 3 & 42.0 \\
\hline 0 & 3 & 0 & 9.4 & 2 & 3 & 0 & 29.0 \\
\hline 0 & 3 & 1 & 13.0 & 2 & 3 & 1 & 36.0 \\
\hline 0 & 3 & 2 & 16.0 & 2 & 3 & 2 & 44.0 \\
\hline 0 & 3 & 3 & 19.0 & 2 & 3 & 3 & 53.0 \\
\hline 1 & 0 & 0 & 3.6 & 3 & 0 & 0 & 23.0 \\
\hline 1 & 0 & 1 & 7.2 & 3 & 0 & 1 & 39.0 \\
\hline 1 & 0 & 2 & 11.0 & 3 & 0 & 2 & 64.0 \\
\hline 1 & 0 & 3 & 15.0 & 3 & 0 & 3 & 95.0 \\
\hline 1 & 1 & 0 & 7.3 & 3 & 1 & 0 & 43.0 \\
\hline 1 & 1 & 1 & 11.0 & 3 & 1 & 1 & 75.0 \\
\hline 1 & 1 & 2 & 15.0 & 3 & 1 & 2 & 120.0 \\
\hline 1 & 1 & 3 & 19.0 & 3 & 1 & 3 & 160.0 \\
\hline 1 & 2 & 0 & 11.0 & 3 & 2 & 0 & 93.0 \\
\hline 1 & 2 & 1 & 15.0 & 3 & 2 & 1 & 150.0 \\
\hline 1 & 2 & 2 & 20.0 & 3 & 2 & 2 & 210.0 \\
\hline 1 & 2 & 3 & 24.0 & 3 & 2 & 3 & 290.0 \\
\hline 1 & 3 & 0 & 16.0 & 3 & 3 & 0 & 240.0 \\
\hline 1 & 3 & 1 & 20.0 & 3 & 3 & 1 & 460.0 \\
\hline 1 & 3 & 2 & 24.0 & 3 & 3 & 2 & 110.0 \\
\hline 1 & 3 & 3 & 29.0 & 3 & 3 & 3 & $>1100.0$ \\
\hline
\end{tabular}

Source: ABNT MB-3463 [30].

Table 1. Most probable number (MPN) with 95\% confidence limits for various combinations of positive results, using three tubes per series to inoculate $1 \mathrm{~mL}$ of dilutions $0.1 ; 0.01$ and $0.001 \mathrm{~g}$ of honey/ml.

\begin{tabular}{llllll}
\hline Example & \multicolumn{2}{l}{ Dilution $(\mathrm{g} / \mathrm{mL})$} & \multicolumn{2}{c}{ Tube combination MPN/g } \\
\hline & 0.1 & 0.01 & 0.001 & & \\
\hline 1 & $3 / 3$ & $3 / 3$ & $1 / 3$ & $3,3,1$ & 460 \\
2 & $3 / 3$ & $0 / 3$ & $0 / 3$ & $3,0,0$ & 23 \\
3 & $2 / 3$ & $1 / 3$ & $1 / 3$ & $2,1,1$ & 20 \\
\hline
\end{tabular}

Table 2. Examples using dilution $(\mathrm{g})$ combining $0.1 ; 0.01 ; 0.001 \mathrm{~g} / \mathrm{mL}$. 


\subsection{Yeast and mould counting}

Counting of viable fungi is applicable to honey as it is an acidic food, with a $\mathrm{pH}$ of less than 4.5 and relatively low moisture. Fungi are affected little by variations in the $\mathrm{pH}$ range 3.0-8.0. The moulds grow below $\mathrm{pH} 2.0$ and several yeasts below 1.5. When the $\mathrm{pH}$ deviates from the optimal, which is generally close to 5.0, the growth rate of colonies decreased and, if there are other inhibition factors, such as water or nutrient temperature activity, its restrictive effect on the growth rate becomes stronger [23].

Its presence at high levels in honey can provide various types of information; for example, the poor hygienic conditions of equipment, multiplying in the product due to failures in processing and/or storage. MERCOSUL GMC resolution $n^{\circ} 15$ of 1994 approved the Technical Regulations for the Identity and Quality of honey, in view of resolutions $n^{\circ} 18$ of 1992 and n ${ }^{\circ} 91$ of 1993 of the Common Market Group [17], in which, in terms of hygiene, honey must be free of foreign inorganic or organic substances in its composition, such as insects, larvae and grains of sand, and should not exceed the maximum levels tolerable for microbiological contamination or toxic waste. Its preparation should be carried out according to the General Principles of Food Hygiene recommended by the Codex Alimentarius Commission-FAO/ WHO [15]. In terms of fungi, up to 100 colony forming units per gram are tolerated in honey (CFU/g) [17].

Moulds are filamentous, multicellular fungi, and may be present in the soil, air, water and raw organic decomposition. They are generally aerobic and less demanding than other yeasts in terms of humidity, $\mathrm{pH}$, temperature and nutrients. They can absorb any carbon source derived from food. As a nitrogen source, they can use nitrate, ammonia and organic nitrogen. They only grow on the surface of honey when in contact with air, as it is a food rich in carbohydrates and acids $[23,31]$.

Yeasts are classified as non-filamentous fungi whose form is unicellular and can be spherical, ovoid, cylindrical or triangular. They are usually spread by insect vectors and by wind and air currents [32]. For growth yeasts require moisture more than that required by moulds and less than that required by bacteria, with an ideal temperature range for growth at around 25 and $30^{\circ} \mathrm{C}$. The growth of the osmophilic yeasts which are part of the micro-biota of importance of honey is favoured as the liquid substrate provides a greater opportunity for the development of anaerobic conditions, due to possessing the ideal acid $\mathrm{pH}$ for use in the fermentation by which the yeast is transformed into sugar, which is used as an energy source in alcohol, when the water activity value is at least 0.65 [31,33]. According to Pitt and Hocking [34], most osmophilic yeasts are of the genus Zygosaccharomyces, including Z. rouxi, Z. bailii and Z. bisporus. To control these microorganisms in honey the application of good hygiene practices is required, and it must be ensured that water activity or moisture content is within acceptable limits [15]. When the honey extracted from the beehive has a lower water activity than 0.60 the multiplication of osmophilic yeast does not occur.

Method: based on the verification of the ability of these microorganisms to develop in a culture media with a $\mathrm{pH}$ around 3.5 and incubation temperature $25 \pm 1^{\circ} \mathrm{C}$. The use of acidified mediums selectively favours the growth of fungi, inhibiting most of the bacteria present in food [2]. 
- Plate preparation process: dilute the potato dextrose agar (PDA) medium; cook in a water bath to $46-48^{\circ} \mathrm{C}$; acidify the medium to $\mathrm{pH} 3.5$ by adding $1.5 \mathrm{~mL}$ of tartaric acid $10 \%$ solution for each $100 \mathrm{~mL}$ of the medium; pour $15-20 \mathrm{~mL}$ into the plates; wait to solidify on a flat surface; identify the plates, before use, dry the semi-open plates in a kiln at $50^{\circ} \mathrm{C}$ for about $15 \mathrm{~min}$ utes or in a laminar flow exposing the surface for the time required for complete drying.

- Sample preparation: aseptically remove $25 \mathrm{~g}$ of the sample, open the packaging in an aseptic chamber, close to the flame of the Bunsen burner and taking care so that all the tools and utensils used are sterilized and flamed at the time of use.

- Preparation of dilutions: add $225 \mathrm{~mL}$ of peptone water $0.1 \%$ and mix, obtaining the first dilution $\left(10^{-1}\right)$. For the second dilution $\left(10^{-2}\right)$, transfer $10 \mathrm{~mL}$ of the first dilution to $90 \mathrm{~mL}$ of peptone water $0.1 \%$ and for the third dilution $\left(10^{-3}\right)$, using the same procedure (Figure 3 ).

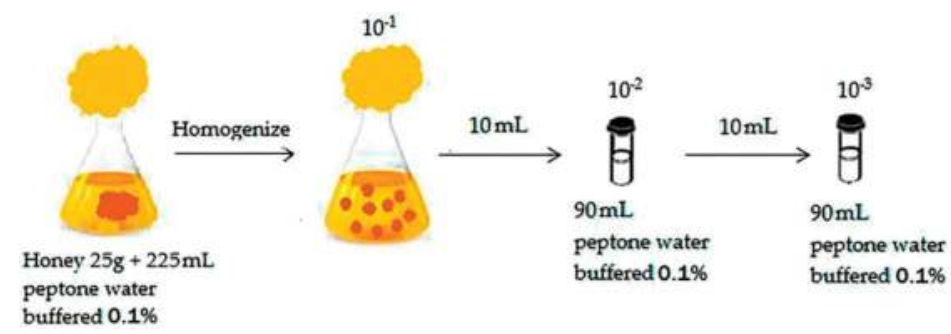

Figure 3. Procedure for the preparation of dilutions $10^{-1} ; 10^{-2}$ and $10^{-3}$.

- Inoculation: carry out surface plating, adding $0.1 \mathrm{~mL}$ of each dilution to the plates with the potato dextrose agar or dichloran-glycerol agar; with the help of Drigalski spatula or a hockey stick shaped rod spread the inoculum over the agar surface until its complete absorption.

- Incubation: incubate at $25^{\circ} \mathrm{C}$ for 5 days, without inverting the plates, in stacks of no more than three plates, in the dark. After incubation, check the presence of colonies of yeasts and moulds, count them and carry out the calculations (Figure 4).

- Count the colonies and calculate results: select the plates with 15-150 colonies with a colony counter. In the selected plate count and note separately the colonies with a filamentous appearance, characteristic of moulds. On the same plate count the other colonies, which can be yeast or bacteria, eventually capable of growth. Select at least five of these colonies and verify the morphology of the cells with a microscope observing if the culture is of yeasts, bacteria or a mixture of both. Colonies which present yeasts or mixtures of yeasts and bacteria are considered confirmed.

Determine the number of yeast colonies on the plate based on the confirmed percentage. For example, of 30 colonies counted, five were submitted to confirmation and three were confirmed as yeast $(60 \%)$, so the number of yeast colonies on the plate is $30 \times 0.6=18$. To calculate the number of colony forming units per gram $(\mathrm{CFU} / \mathrm{g})$ of yeasts and moulds, multiply the number of colonies by ten and by the inverse of the dilution. The total calculation of both is 


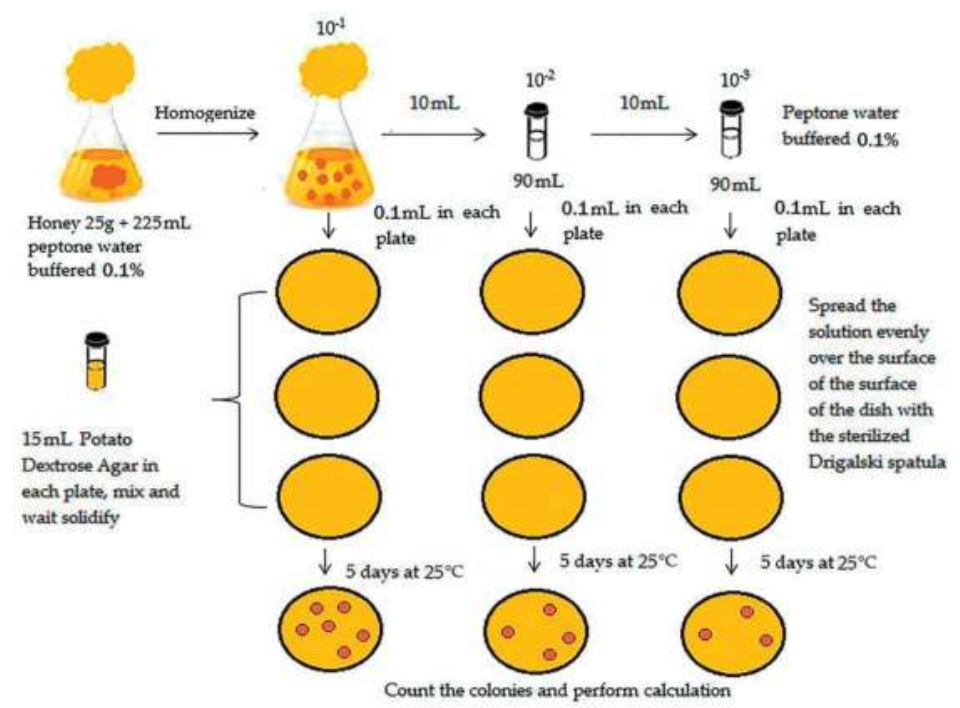

Figure 4. Procedure for the preparation and inoculation of dilutions $10^{-1} ; 10^{-2}$ and $10^{-3}$ on the plates of potato dextrose agar.

carried out by adding the number of mould colonies and the number of colonies confirmed as yeast and multiplying by the inverse of the dilution according to Eq. (1).

$$
\mathrm{CFU} / \mathrm{g}=\text { number of colonies } \times \text { Dilution reverse } \times 10
$$

For example:

Dilution $10^{-2}$ (inoculated $0.1 \mathrm{~mL}$ )

Total typical colonies of mould on plate $=30$

Presumptive colonies of yeast on plate $=40$, five to submit for confirmation, confirmed four $(80 \%)$

Total yeast colonies on plate $=40 \times 0.8=32$

CFU $/ g$ moulds $=30 \times 10^{2} \times 10=3.0 \times 10^{4}$

$\mathrm{CFU} / \mathrm{g}$ yeast $=32 \times 10^{2} \times 10=3.2 \times 10^{4}$

CFU/g of yeasts and moulds $=(30+32) \times 10^{2} \times 10=6.2 \times 10^{4}$

\subsection{Salmonella sp}

Species of the Salmonella genus are agents of human and animal intestinal infections. Among the agents of foodborne illnesses, Salmonella is one of the most responsible for fatalities and clinical complications. Moreover, the high morbidity and mortality rate and incidence in humans and animals result in significant spending on medications and hospitalizations. The inspection and monitoring of food is aimed at the control and prevention of members of this group and the effects of their presence in food. Compliance with good manufacturing practices and control programs should include a certificate of compliance with the measures adopted, especially for this bacterial genus [23].

Method: the method for detecting Salmonella in food is based on its presence or absence, developed to guarantee detection even in unfavourable situations. The procedures recommended 
by various regulatory bodies basically follow five steps that can be applied to any type of food $[2,3,5,10,11,13]$.

- Pre-enrichment in non-selective broth: the objective is the recovery of injured cells, obtained by incubating the sample in non-selective conditions for at least 18 hours. The most commonly used medium is buffered peptone water and lactose broth. This step consists of aseptically weighing $25 \mathrm{~g}$ of honey in $225 \mathrm{~mL}$ of BPW $1 \%$ and incubating at $35^{\circ} \mathrm{C}$ for $18-24$ hours. Finally, adjust the $\mathrm{pH}$ to $6.8-6.9$ (Figure 5)

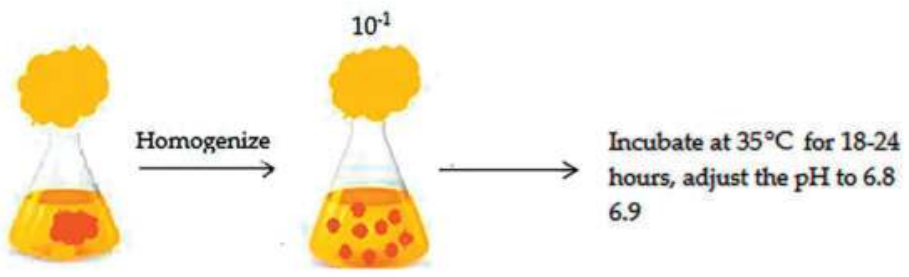

\footnotetext{
Honey $25 \mathrm{~g}+225 \mathrm{~mL}$

peptone water buffered

$1 \%$ or Lactose broth
}

Figure 5. Procedure for the pre-enrichment non-selective broth.

- Selective enrichment broth: the objective is to inhibit the multiplication of the accompanying micro-biota and promoting the preferential increase of the number of Salmonella cells by incubating a pre-enriched sample in selective broth for 18-24 hours. The use of two different media is recommended because of the resistance of Salmonella to different selective agents of the medium which varies from strain to strain. The most recommended means are RappaportVassiliadis soy broth (RVS) and selenite cystine broth (SC) as follows (Figure 6):

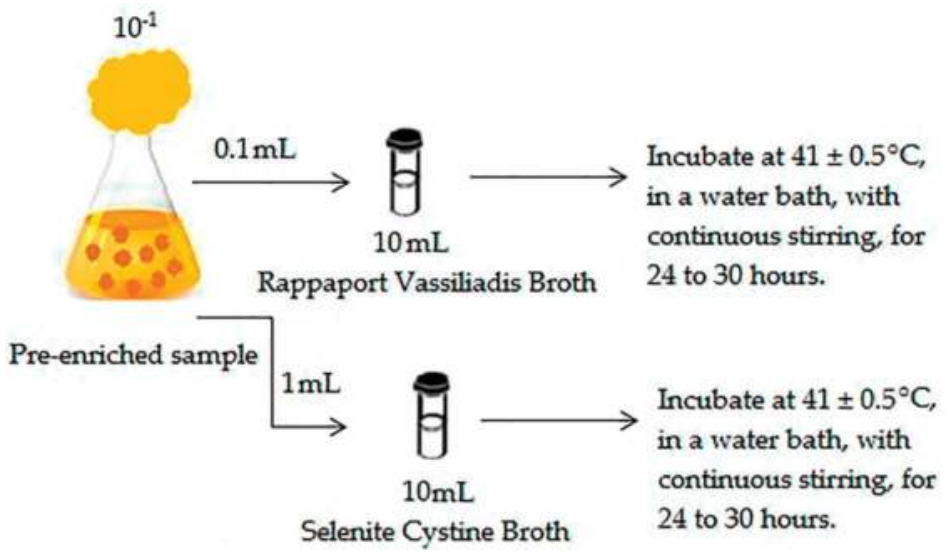

Figure 6. Procedure for the pre-enrichment selective broth. 
- Inoculation in Rappaport Vassiliadis broth: pipette out $1 \mathrm{~mL}$ of pre-enriched samples and transfer to tubes containing $10 \mathrm{~mL}$ Rappaport Vassiliadis broth. Incubate the tubes at $41 \pm 0.5^{\circ} \mathrm{C}$ in a water bath, preferably with continuous agitation or circulation of water, for 24-30 hours.

- Inoculation in selenite cystine broth: pipette out $1 \mathrm{~mL}$ of pre-enriched samples and transfer to tubes containing $10 \mathrm{~mL}$ of selenite cystine broth. Incubate the tubes at $41 \pm 0.5^{\circ} \mathrm{C}$ in a water bath for 24-30 hours.

- Selective differential plating: the aim is to promote the preferential development of Salmonella colonies, whose typical characteristics differentiate them from competitors, for subsequent biochemical and serological confirmation. The use of more than one type of culture medium is recommended. The most commonly used media are those that differentiate Salmonella by the non-fermentation of lactose and by $\mathrm{H}_{2} \mathrm{~S}$ production, such as hektoen enteric agar (HE), xylose lysine deoxycholate agar (XLD) and xylose lysine tergitol-4 agar (XLT-4). As there are Salmonella strains which ferment lactose or do not produce $\mathrm{H}_{2} \mathrm{~S}$, it is important that the second or third plating medium is not based on these characteristics. One option is the brilliant green phenol red lactose sucrose agar (BPLS) or brilliant green agar (BG) based on the fermentation of lactose but not the production of $\mathrm{H}_{2} \mathrm{~S}$, and bismuth sulphite agar (BS), which is based on $\mathrm{H}_{2} \mathrm{~S}$ production and not lactose fermentation. Rambach agar can also be used in this step. Add $0.1 \mathrm{~mL}$ of novobiocin solution $4 \%$ to $100 \mathrm{~mL}$ of brilliant green phenol red lactose sucrose agar. Incubate all plates at $35^{\circ} \mathrm{C}$ for 24 hours (Figure 7).

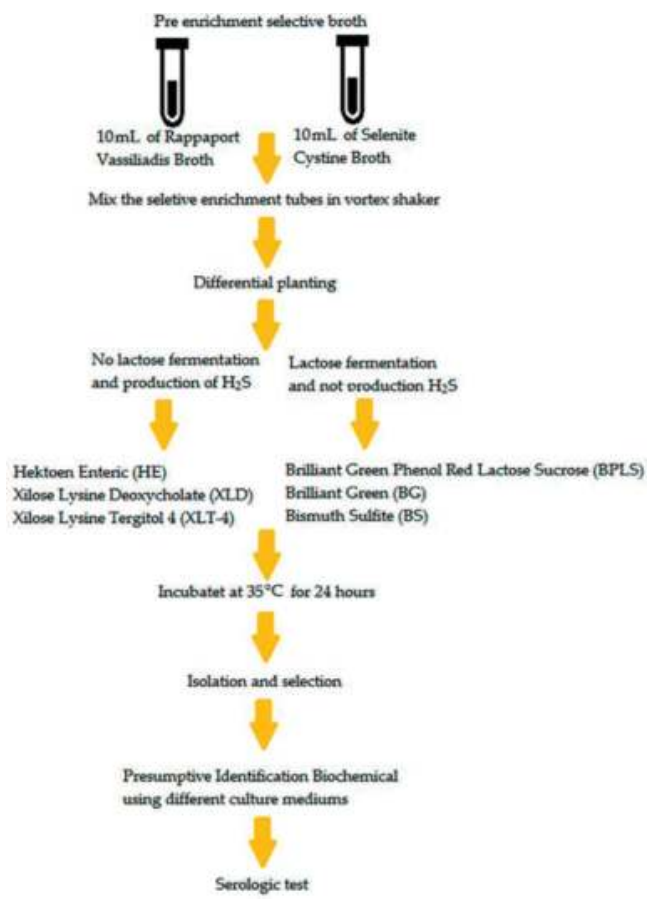

Figure 7. Procedure for differential plating and biochemical identification. 
- Isolation and selection: depending on the medium, the Salmonella colonies present different colours after the incubation period: in hektoen enteric agar the colonies are green or bluish green, revealing or otherwise the production of hydrogen sulphide $\left(\mathrm{H}_{2} \mathrm{~S}\right)$ (dark centre); in xylose lysine deoxycholate agar the colonies are red with the production of hydrogen sulphide $\left(\mathrm{H}_{2} \mathrm{~S}\right)$ (dark centre); in xylose lysine tergitol-4 agar the colonies are red; in brilliant green phenol red lactose sucrose agar the colonies are colourless or have a pink colour, between clear and slightly opaque and when surrounded by fermenting microorganisms of lactose, may present a greenish-yellow colour. With brilliant green agar the colonies are red; and with bismuth sulphite agar (BS) the colonies are winged with a black centre.

- Presumptive biochemical identification (screening methods): the aim is to verify that the typical colonies obtained from the plates are truly Salmonella, specifically strains of Salmonella enterica subsp. Enterica, which is the main target for food analysis and which has a biochemical profile which is considered typical in detection assays (Table 3). Once the suggestive colonies have been selected by the indicating methods, they will be transferred to the screening mediums:

\begin{tabular}{llll}
\hline Culture medium used & $\begin{array}{l}\text { Positive or negative } \\
\text { reaction }\end{array}$ & Colour of culture medium & Positive or negative percentage \\
\hline Glucose TSI (gas) & + & Yellow medium with gas & 100.0 \\
Glucose TSI (acid) & + & Yellow medium/red bevel & 91.9 \\
Lactose TSI & - & Red medium & 99.2 \\
Sucrose TSI & - & Red medium & 99.5 \\
TSI H $\mathrm{H}_{2}$ & + & Dark medium & 91.6 \\
LIA & + & Violet copper medium $+\mathrm{H}_{2} \mathrm{~S}$ & 98.0 \\
& & production & \\
SIM H $\mathrm{S}_{2}$ & + & Dark medium colour the base & 97.0 \\
SIM (indole) & - & No red ring & 98.9 \\
SIM (motility) & + & Diffusion in inoculation zone & 97.0 \\
Urea hydrolysis & - & Yellow medium & 99.0 \\
Lysine decarboxylase & + & Violet medium $+\mathrm{H}_{2} \mathrm{~S}$ & 94.6 \\
Ornithine decarboxylase & + & Violet medium $+\mathrm{H}_{2} \mathrm{~S}$ & 97.0 \\
Voges-Proskauer reaction & - & No red ring & 100.0 \\
\hline
\end{tabular}

Table 3. Colour of culture medium and Salmonella spp. positive and negative percentage in biochemistry test after $24 \mathrm{~h}$ incubated at $35^{\circ} \mathrm{C}$.

(1) Triple sugar iron agar (TSI Agar): this medium is used to differentiate Gram-negative rods based on fermentation and the gas production from the carbohydrates: glucose, lactose and sucrose and the production of hydrogen sulphide. For the test, inoculate the triple sugar iron agar by deep, grooved stabbing motions and in inclined surface of the bevel. Incubate at $36^{\circ} \mathrm{C}$ 
for 18-24 hours. In the presence of Salmonella, the glucose is rapidly depleted, and is verified by the appearance of a yellow colour in the base. After the fermentation of glucose, the aerobic degradation of the protein substrate of the medium occurs, producing ammonia, which gives the medium an alkaline $\mathrm{pH}$, changing the bezel colouring to intense pink. Gas production is indicated by the formation of blisters or cracks in the medium. Most Salmonellas do not ferment sucrose and lactose. When these two sugars are not fermented, the apex keeps its original colour-amber. The production of $\mathrm{H}_{2} \mathrm{~S}$ is indicated by the black colour at the base of the central portion of the tube. Microorganisms such as Proteus mirabilis, Edwardsiella tarda, C. freundii and Salmonella spp may exhibit a similar behaviour.

(2) Lysine-iron agar (LIA Agar): this medium is used to verify the decarboxylation of lysine which is evidenced by the violet colouration-alkaline-of the base. When this does not occur, the yellow colour indicates only the fermentation of glucose. The positive reaction for the deamination of lysine is visible at the apex (coppered violet) and the production of $\mathrm{H}_{2} \mathrm{~S}$ by the appearance of black colouring from the base to the central portion of the tube.

(3) Hydrolysis of urea (Stuart urea broth and Christensen urea agar: determines the ability of a microorganism to degrade, enzymatically, the urea by urease, with the formation of two molecules of ammonia and carbon dioxide, with the alkalization of the medium and increased $\mathrm{pH}$. Streak only on the surface of the broth or the urea agar. Incubate at $36^{\circ} \mathrm{C}$ for 18-24 hours. The colour is caused by addition of the phenol red to the medium. The positive reaction turns the yellow (the original colour of the medium) to intense pink. Proteus features a more intense reaction; the negative reaction maintains the yellow colour of the medium. A total of $99 \%$ of the Salmonella strains do not produce urease.

(4) Indole test (SIM medium): check the motility of the microorganisms and the $\mathrm{H}_{2} \mathrm{~S}$ and indole production capacity. Inoculate the culture medium. Incubate at $36^{\circ} \mathrm{C}$ for $24-30$ hours. The motility reading is characterized by the diffusion of growth throughout the medium. If restricted to the line of streaking, it indicates that the microorganism is immobile. After the motility reading, verify $\mathrm{H}_{2} \mathrm{~S}$ production by the development of the black colour in the medium. Bacteria that possess the tryptophanase enzyme are capable of hydrolyzing and deaminating the tryptophan with the production of indole, pyruvic acid and ammonia. To verify its production, add a few drops of Kovac's reactive to the tubes; if there is indole production a red ring will form. In most cases (99\%) the strains of Salmonella do not produce indole, do produce $\mathrm{H}_{2} \mathrm{~S}$ and are mobile.

(5) Voges-Proskauer (VP) test: determine the ability of some bacteria to oxidize glucose producing organic acid as a final product. Transfer the microorganism to be tested to test tubes with red broth methyl-Voges-Proskauer (Clark and Lubs medium). Incubate the tubes at $37^{\circ} \mathrm{C}$ for $24-48$ hours. To read, add 5 drops methyl red. Positive: red colour $(\mathrm{pH}<4.0)$; Negative: original medium colour (yellow) $(\mathrm{pH} \geq 6.0)$. The Salmonellas are VP negative. From the VM-VP medium, remove $2 \mathrm{~mL}$ of culture to a new tube and add 15 drops of $\alpha$-naphthol $5 \%$ reagent (reagent $\mathrm{A}$ ) and 5 drops of $\mathrm{KOH} 40 \%$ solution (Reagent B) to each tube for each $\mathrm{ml}$ of culture medium. Agitate the tubes so that there is oxygenation of the medium. Wait for 10-30 minutes. Positive: development of pinkish to red colouring; Negative: absence of pink or red. 
(6) Utilization of citrate (Simmons citrate agar): characterize microorganisms capable of utilizing citrate as the sole carbon source, which cause the $\mathrm{pH}$ of the culture medium to increase due to the metabolism of citrate ions. Transfer by streaking the bacteria to be tested on the inclined surface of the Simmons citrate agar with a needle. Incubate the tubes at $37^{\circ} \mathrm{C}$ for $24-48$ hours. The Salmonella strains (95\%) are positive, except for the serotypes Typhi, Paratyphi A, Pullorum and Galinarum (100\% of negative strains) and Choleraesuis (75\% of negative strains), and can utilize the citrate and extract nitrogen ammonium salt, leading to alkalization of the medium from the conversion of the $\mathrm{NH}_{3}$ in ammonia hydroxide $\left(\mathrm{NH}_{4} \mathrm{OH}\right)$. After incubation, examine the cultures contained in the tubes with an inclined medium and assess the presence or absence of bacteria growth, checking for any change in colour: if positive, the medium becomes intense blue, especially at the apex; if negative, the natural colour of the medium does not change, but remains green.

(7) Lysine decarboxylation: determine the enzymatic ability of a microorganism by decarboxylating the amino acid lysine, with the subsequent alkalization of the medium, by the presence of the enzyme lysine decarboxylase. The colour is promoted by bromocresol (pupura indicator), which has a violet colour at alkaline $\mathrm{pH}$. Inoculate with lysine iron agar with deep stabbing incisions, streaking the inclined surface of the bevel. Add sterile seal (Vaseline), to avoid the contact of the medium with air and the consequent appearance of a false alkalization on the surface of the medium by aerobically degrading the protein substrate. Incubate at $36^{\circ} \mathrm{C}$ for $24-30$ hours. The majority of Salmonellas (96\%) can produce lysine decarboxylase. During the initial period of incubation, the medium turns yellow due to the fermentation of glucose present. If the amino acid is decarboxylated, alkaline amines are formed and the colour of the medium returns to the original purple colour, with the production of $\mathrm{H}_{2} \mathrm{~S}$.

(8) Motility indole-8-ornithine (MIO) and motility indole-lysine (MIL): inoculate by deep stabbing and incubate at $24 \mathrm{~h} / 35^{\circ} \mathrm{C}$. These mediums demonstrate the decarboxylation of ornithine or lysine amino acid, mobility and indole production. Mobility is interpreted by microorganism dissemination in the inoculation area (growth only in line of incision = negative motility); decarboxylation of ornithine or lysine is evidenced by a purple (alkaline) colouring in the base which neutralizes the acid (yellow) formed by the fermentation of glucose. Indole production is observed by the formation of a red ring after adding 2-4 drops of Kovacs reagent to the medium surface.

(9) In malonate-phenylalanine broth: determines the capacity of the microorganism to deaminate phenylalanine in phenylpyruvic acid, by its enzymatic activity, with consequent acidity. Inoculate the surface of the phenylalanine agar by streaking. Incubate at $36 \pm$ $1^{\circ} \mathrm{C}$ for $18-24$ hours. Add 2-3 drops of $10 \%$ ferric chloride solution. In a negative test, as there is no phenylpyruvic acid, the colour of the reactive $\mathrm{FeCl} 3$ remains yellow. The change of the colour on the bevel surface to green indicates the deamination reaction of the phenylalanine. Salmonella does not deaminate phenylalanine, with the colour of the medium remaining unchanged.

(10) Dulcitol broth: dulcitol fermentation occurs by turning the phenol red indicator to yellow. Most Salmonella are dulcitol positive (yellow). 
Observations:

(1) These percentages indicate the incidence of strains with reactions marked as + or -.

(2) S. Typhi is anaerogenic;

(3) Salmonella enterica arizonae: + or - reaction to lactose, positive $\beta$-galactosidase;

(4) Salmonella enterica salamae: - reaction to lactose and $\beta$-galactosidase;

(5) Salmonella pullorum and Salmonella gallinarum are immobile;

(6) S. arizonae absorbs the malonate;

(7) S. arizonae does not ferment the dulcitol;

(8) $25 \%$ of the Salmonella strains are citrate-negative.

In general, the various regulatory bodies also recommend the use of miniaturized commercial kits which allow a great number of biochemical tests.

- Serological test using fast agglutination

Serologic confirmation verifies the presence of ' $\mathrm{O}$ ', ' $\mathrm{V}^{\prime}$ and ' $\mathrm{H}^{\prime}$ antigens by agglutination tests with polyvalent antisera:

- Add approximately $2 \mathrm{~mL}$ of saline solution $0.85 \%$ to the culture in inclined nutrient agar and homogenize;

- With a Pasteur pipette deposit two drops of the suspension separately on a glass slide;

- Add one drop of anti-Salmonella polyvalent 'O' serum to one of the droplets of the suspension on the slide and mix, and add one drop of saline to the other;

- Perform the reading under illumination against a dark background for 1-2 minutes.

Classify the reaction as follows:

- Positive: presence of agglutination only in the cultivation + antiserum mixture.

- Negative: no agglutination in either mixture.

- Nonspecific: presence of agglutination in both mixtures (rough forms).

The cultures with positive results in the agglutination test with the anti-Salmonella polyvalent 'O' serum should be sent to certified laboratories for final classification.

\subsection{Determination of the antibacterial activity of honey}

With the exaggerated use of certain compounds such as ampicillin, cephalexin and others, bacteria have developed resistance to antibiotics, leading to studies for new compounds with 
antimicrobial activity from different natural products such as honey [35]. Since the beginning of civilization, honey has had a cultural importance that is not restricted merely to food but also includes use as folk medicine and as a cosmetic [36]. It has different therapeutic properties and is antimicrobial, antifungal, antioxidant, antiviral, anti-parasitic and anti-inflammatory $[35,37]$.

Honey is a substance prepared from the nectar of flowers (floral honey), plant exudates, or the excretion of sucking insects of plants (honeydew) [18]. The enzyme content present in honey is differentiated, as it depends on the species of bee, soil characteristics, seasonal factors such as temperature, rainfall and bee flora, with the product distinguished by the amount of organic acids, enzymes, vitamins, flavonoids, minerals and an extensive range of organic compounds, contributing to its colour, odour and specific flavour [38].

The antimicrobial action of honey is related to soil characteristics, atmospheric conditions, plant diversification, low water activity ( $\mathrm{Aw}$ ), high osmotic pressure, low $\mathrm{pH}$, the glucose/oxidase system of hydrogen peroxide formation, the presence of phytochemical constituents and volatile substances [39]. These different qualities together create differences in the expression of antimicrobial activity of honey [40]. Molan [41] reported that in super-saturated sugar solutions, honey has a low water activity, which, as well as the natural acidification of the medium, creates unfavourable conditions for bacterial growth. In the presence of water and oxygen, the enzyme glucose oxidase converts glucose into gluconic acid and hydrogen peroxide, which are considered relevant substances for antioxidant action, which affect the microorganisms and preserve the sterility of honey during maturation [42].

Method: Preparation of bacterial inoculum and standardization: from the pure culture of bacteria preserved under refrigeration at $6^{\circ} \mathrm{C}$, proceed to the preparation and standardization of the inoculum, in accordance with to the Clinical and Laboratory Standards Institute CLSI M07-A9 document [43]. Transfer three to five colonies of the selected strain to a test tube with a screw top containing 4-5 mL Miller Hinton broth (MHB), incubate the culture in the broth at $35^{\circ} \mathrm{C}$ for $18-24$ hours and standardize the bacterial suspension in $0.85 \%$ saline solution, obtaining an optical turbidity comparable to standard McFarland solution 0.5 to the naked eye under illumination against a white background card with contrasting black lines. Dilute the inoculum at a ratio of $1: 10$ in saline solution $0.85 \%$ resulting in a concentration of $10^{7} \mathrm{CFU} / \mathrm{ml}$.

- Antimicrobial susceptibility testing-broth microdilution method: perform as per Clinical and Laboratory Standards Institute CLSI M07-A9 document [43], which is used to verify the minimum inhibitory concentration (MIC) by the broth microdilution method. To perform the test use $96 \mathrm{U}$ bottom wells with markings indicating the position of each well, lines (A-H) and columns (1-12) (Figure 8).

Pipette out $100 \mu \mathrm{L}$ of Mueller Hinton broth in each well and then perform a dilution series of different samples of honeys, with each honey sample in a different line. For serial dilution, pipette out $100 \mu \mathrm{L}$ of honey in the first well, homogenize, remove $100 \mu \mathrm{l}$ from the first well and transfer to the second well, remove $100 \mu \mathrm{L}$ from the second and transfer to the third; and so on, until the ninth well of each row. This provides the following honey concentrations in percentages (\%) (Table 4$)$. 


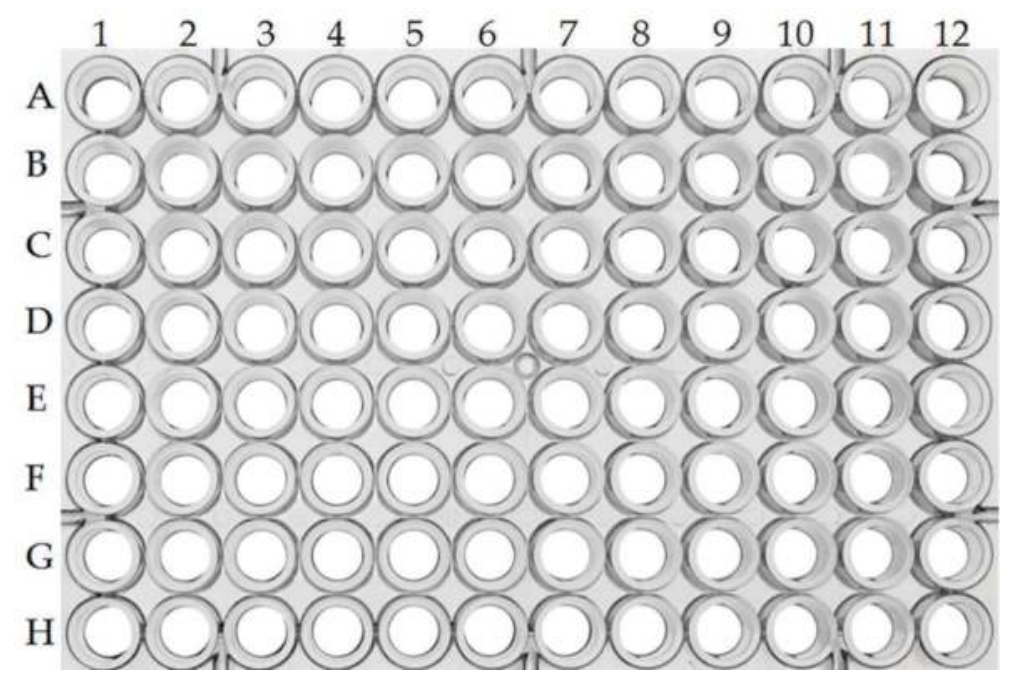

Figure 8. 96 well U bottom micro-plate with markings indicating the position of the lines (A-H) and columns (1-12).

\begin{tabular}{ll}
\hline No of wells & Honey (\%) \\
\hline 1 & 50.000 \\
2 & 25.000 \\
3 & 12.500 \\
4 & 6.250 \\
5 & 3.125 \\
6 & 1.560 \\
7 & 0.780 \\
8 & 0.390 \\
9 & 0.195 \\
\hline
\end{tabular}

Table 4. Honey concentrations in percentage (\%) for wells from 1 to 9 .

As a bacterial control (without the addition honey), use well 10, and as a broth control (without the addition of honey and inoculum), use well 11. After adding the honey, inoculate $5 \mu \mathrm{L}$ of a standardized suspension of the bacteria in question in each well, except the broth control well, so that the end of test bacteria concentration is $5 \times 10^{4} \mathrm{CFU} /$ well. Identify the microplates, incubate in a bacteriological incubator at $35^{\circ} \mathrm{C}$ for 24 hour. After 24 hours of incubation the micro-plates are analysed to determine the MIC, which is defined as the lowest concentration of honey in which there is no visible growth after incubation. Finally, analyse the well 
contents indicated with the minimum inhibitory concentration by microscope to confirm if there is growth or not. Perform the tests in triplicate for each of the bacteria analysed.

\subsection{Microscopy of honey}

Microscopy of food is a technique used to identify foreign components in products, making it possible to check if they comply with standards. Several countries use government and health-related agencies to ensure food safety, by monitoring their supply chains. MERCOSUR GMC Resolution N ${ }^{\circ}$ 15/1994 approved the Technical Regulations for the Identity and Quality of Honey based on resolutions $N^{\circ}$. 18/1992 and $N^{\circ}$ 91/1993 of the Common Market Group [17]. Normative Instruction $N^{\circ} .11$ of October 20, 2000 approved the Technical Regulations for the Identity and Quality of Honey [18] and pursuant to Ordinance $N^{\circ} .46$ of 10 February, 1998 the Ministry of Health and the Ministry of Agriculture and Supply established the adoption of the Hazard Analysis and Critical Control Point (HACCP) system by the Food Industries for animal products [44]. This system is recommended by international bodies such as the World Trade Organization (WTO) and the World Health Organization [16], both forming part of the United Nations (UN), for Food and Agriculture.

In compliance with these standards, any problem identified in honey lots should be corrected immediately and possible causes should be identified. Once the failures are identified, the company must take corrective action to prevent new problems arising. These corrective actions must be validated through audits and microbiological tests that prove the definitive correction of the non-compliance.

According to the macroscopic and microscopic criteria established in Brazil [18] honey must be free from any foreign substance. In practice, dirt present in honey may come from two sources - the first occurs inside the beehive, and is more difficult to control as it is added to honey by bees which carry fragments of other insects, pollen and soil. Secondary sources are present from harvesting through the steps of obtaining, processing, and distribution of honey [45], and include wax fragments, propolis, larvae, wood fragments and among others. Use of Good Apicultural Practices reduces the risk of secondary contamination ensuring a quality product in accordance with standard rules [46]. Camargo [47] recommends the procedures of the Good Apicultural Practices should be applied during the processing of honey, including: use stainless steel trays for stacking wooden beehives, allow no contact between the wooden beehive and the ground; choose honeycombs free of bees, larvae, or pollen; open wooden beehives only in the reception of the honey house for prior cleaning (removing of adhered bees, wax and propolis); filter the honey with the aid of sieves with meshes of various diameters, pumps or filters; decant the honey for soil removal at lower densities.

Method: The analysis of dirt and foreign matter can be performed following the method of the Association of Official Analytical Chemistry AOAC [9] No. 945.79, which uses filtration of the sample in the presence of nitric acid. The method is based on dissolving $100 \mathrm{~g}$ of the honey sample in $200 \mathrm{~mL}$ of distilled water which is heated and acidified with $5 \mathrm{~mL}$ of nitric acid $\left(\mathrm{HNO}_{3}\right)$ at a concentration of $6 \mathrm{M}$. Filter the sample in a Buchner funnel. Mark four quadrants 
on filter paper. Analyse using a stereoscopic microscope with a total multiplication of 100× and confirm the type of sediment between slide and cover slip under an optical microscope with a multiplication of $100-400 \times$.

\subsection{Clostridium botulinum}

The pathogenic microorganism of importance in honey is the Clostridium botulinum bacterium, which is capable of producing spores. Bacterial spores are latent and resistant to adverse environmental conditions and can thus endure processing and storage for long periods. Contamination of honey by C. botulinum spores occurs within the colony, making practical procedures for its prevention difficult.

In practice, the bees carry the spores of this bacterium in their legs and antennae, taken from the soil where they land constantly. These spores begin to grow in the colonies, and remain in the combs together with the honey. Contamination is also possible in the act of collecting the product if hygiene practices are poor, and further contamination can occur through contact with the ground. Once present in honey, it survives in the medium without competition from other microorganisms. The incidence of spores in honey may also be related to multiplication and sporulation in dead bees and their larval forms in the colonies [48].

Honey is the only food recognized as a risk factor for infant botulism. Although there have been many cases of occurrence of infant botulism from honey contaminated with Clostridium botulinum, literature on this topic remains scarce. Consequently, in Brazil the administration of honey to children is not recommended, especially in the breastfeeding phase. This practice is also adopted in the United States, the United Kingdom and Argentina, where spores were isolated [49].

This disease occurs in children under 12 months, and 95\% of cases occur in the first 6 months of life, when honey is used as a sweetener for bottles and juices as well as to bathe pacifiers to soothe the child. A child's intestine possesses an immature flora. The intake of honey with spores leads to germination, multiplication and the production of botulinum neurotoxins in the intestinal lumen, causing many problems for the health of children [50]. The consumption of honey by adults or older children does not seem to provide any kind of risk in relation to botulism. Consequently, it is recommended by the World Health Organization and the US Centers for Diseases that honey should not be given to infants under 6 and 12 months, respectively $[16,31]$.

Honey added as an ingredient in commercial infant formulas for babies aged less than 1 year must be thermally processed to destroy botulinum spores. No reports exist about the use of honey as an ingredient in other foods which have caused botulism. The analysis of honey for C. botulinum is not recommended as a control measure [49].

The microbiological analysis of honey detects product contamination. The presence of microorganisms or their spores in honey can cause its deterioration and result in enzymatic changes, the production of mycotoxins and even consumer illness. Due to the therapeutic properties attributed to honey, antimicrobial evaluation is essential to contribute to the quality maintenance of this product, adding to its commercial value. 


\section{Author details}

Maria Josiane Sereia ${ }^{1 *}$, Marcia Regina Ferreira Geraldo Perdoncini ${ }^{1}$, Paulo Henrique Março ${ }^{1}$, Rejane Stubs Parpinelli², Erica Gomes de Lima $^{2}$ and Fernando Antônio Anjo ${ }^{3}$

*Address all correspondence to: mjsereia@gmail.com

1 Department of Engineering and Food Technology, Federal Technology University of Parana (UTFPR), Campo Mourāo, Brazil

2 Department of Animal Science, State University of Maringa (UEM), Maringa, Brazil

3 Agricultural Science Center, State University of Maringa (UEM), Maringa, Brazil

\section{References}

[1] Brazil. Ministry of Health. National Sanitary Surveillance Agency. Resolution RDC No. 12 of January 2, 2001. Approves the technical regulation on microbiological standards for food [Internet]. 2001. Available from: http://portal.anvisa.gov.br/documents/ 33880/2568070/RDC_12_2001.pdf/15ffddf6-3767-4527-bfac-740a0400829b [Accessed: 2016-06-14].

[2] Brazil. Ministry of Agriculture and Supply. Normative Instruction No. 6 of August 26, 2003. Official Analytical Methods for Microbiological Analysis for the Control of Products of Animal Origin and Water [Internet]. 2003. Available from: http://sistemasweb.agricultura.gov.br/sislegis/action/detalhaAto.do?method=consultarLegisl acaoFederal [Accessed: 2016-06-14].

[3] Andrews WH, Flowers RS, Silliker J, Bailey JS. Salmonella. In: Downes FP, Ito K, editors. Compendium of methods for the microbiological examination of foods. 4th ed. Washington, DC: American Public Health Association; 2001. pp.357-380.

[4] Downes FP, Ito K. Compendium of methods for the microbiological examination of foods. American Public Health Association. 4th ed. Washington, DC: American Public Health Association; 2001. 676p.

[5] Morton RD. Aerobic plate count. In: Downes FP, Ito K, editors. Compendium of methods for the microbiological examination of foods. 4 th ed. Washington, DC: American Public Health Association; 2001. pp.63-67.

[6] International Commission on Microbiological Specifications for Foods (ICMSF). Microorganisms in Foods 2. Sampling for microbiological analysis: principles and specific applications. 2nd ed. Toronto: University of Toronto Press; 1986. 131 p.

[7] International Commission on Microbiological Specifications for Foods (ICMSF). Microorganisms in Foods 7: Microbiological testing in food safety management. Norwell: Kluwer Academic/Plenum Publishers; 2002. 362 p. 
[8] United States of America. Department of Agriculture. Fact sheets. Production and inspection. risk analysis [Internet]. 2003. Available from: http://www.fsis.usda.gov/Fa ct_Sheets/Risk_Anal ysis/index.asp [Accessed: 2016-08-07).

[9] Association of Official Analytical Chemistry (AOAC). Official methods of analysis. 19th ed. Gaithersburg: Hardcover; 2012. 3000 p.

[10] Andrews WH, Jacobson A, HammackTS. Salmonella.In:Hammack TS, editor. Bacteriological Analytical Manual Online [Internet]. 2001. Available from: http://www. fda.gov/Food/ FoodScienceResearch/LaboratoryMethods/ucm070149.htm [Accessed: 2016-08-06].

[11] United States of America. Department of Agriculture.Food Safety and Inspection Service. Office of Public Health Science. MLG 4.04: isolation and identifcation of Salmonella from meat, poultry and egg products [Internet]. 2014. Available from: http://www.fsis.usda.gov/ wps/wcm/connect/700c05fe-06a2-492a-a6e1-3357f7701f52/MLG-4. pdf?MOD=AJPERES [Accessed: 2016-08-06].

[12] International Organization for Standardization (ISO:6579). Microbiology-General guidance on methods for the detection of Salmonella. 3rd ed. 1993.snp.

[13] International Organization for Standardization (ISO:6579). Microbiology of food and animal feeding stuffs-Horizontal method for the detection of Salmonella. spp. 4th ed. 2002. 27p.

[14] Guzewich JG, Ross MP. Evaluation of Risks Related to Microbiological Contamination of Ready-to-eat Food by Food Preparation Workers and the Effectiveness of Interventions to Minimize Those Risks. Food and Drug Administration.Center for Food Safety and Applied Nutrition [Internet]. 1999. Available from: http://citeseerx.ist.psu.edu/viewdoc/ downlo ad?do $\mathrm{i}=10.1 \cdot 1.410 .843 \&$ rep=rep1\&type=pdf [Accessed: 2016-06-06].

[15] Codex Alimentarius. Codex standard for honey. Food and Agriculture Organization of the United Nations (FAO).World Health Organization (WHO). Rome: Codex Alimentarius Commission; 2001. 8 p.

[16] World Health Organization (WHO). Botulism, fact sheet 270 [Internet]. 2002. Available from: http://www.who.int/mediacentre/factsheets/fs270/en/ [Accessed: 2016-08-20].

[17] Brazil. Ministry of Agriculture and Supply. Administrative Order No. 367 of September 4, 1997. Technical Regulation for Identification and Quality of Honey [Internet]. 1997. Available from: http://sistemasweb.agricultura.gov.br/sislegis/action/detalhaAto.do?me thod=consultarLegislacaoFederal [Accessed: 2016-07-23].

[18] Brazil. Ministry of Agriculture Livestock and Supply. Normative Instruction No. 11 of October 20, 2000. Technical regulation of identity and quality of honey [Internet]. 2000. Available from: http://sistemasweb.agricultura.gov.br/sislegis/action/detalhaAto.do?me thod=consultarLegislacaoFederal [Accessed: 2016-07-23].

[19] Brazil. Ministry of Health. National Sanitary Surveillance Agency. Normative Instruction n.3, dated January 19, 2001. Approves the Technical Regulations for Identity and Quality 
of Apitoxin, Bee Wax, Royal Jelly, Lyophilized Royal Jelly, Bee Pollen, Propolis and Propolis Extract [Internet]. 2001. Available from: http://elegis.bvs.br/leisref/public/showAct.php?id=12479\&word [Accessed: 2016-08-14].

[20] International Organization for Standardization (ISO:6887-1). Microbiology of food and animal feeding stuffs. Preparation of test samples, initial suspension and decimal dilutions for microbiological examination. Part 1: General rules for the preparation of the initial suspension and decimal dilutions. $1999.5 \mathrm{p}$.

[21] International Organization for Standardization(ISO:6887-5). Microbiology of food and animal feeding stuffs. Preparation of test samples, initial suspension and decimal dilutions for microbiological examination. Part 5: Specific rules for the preparation of milk and milk products. $2010.5 \mathrm{p}$.

[22] Imhoff JF, Trüper HG. Purple nonsulfer bacteria. In: Staley JT, editor. Bergey's Manual of Systematic Bacteriology. Vol. 3. Baltimore: Williams \& Wilkins; 1989. pp. 1658-1682.

[23] Silva N, Junqueira VCA, Silveira NFA, Taniwaki MH, Santos RFS, Gomes ARR. [Manual methods of microbiological analysis of food, in Portuguese]. Manual de métodos de análise microbiológica de alimentos. São Paulo: Varela; 2010. 624 p.

[24] Marquezi MC. [Methodological comparison to estimate the most probable number (MPN) of coliform in water samples, in Portuguese]. Comparação metodológica para a estimativa do número mais provável (NMP) de coliformes em amostras de água [dissertation]. Piracicaba: Universidade de São Paulo; 2010.

[25] International Commission on Microbiological Specifications for Foods (ICMSF). Food microorganisms: techniques of microbiological analysis. 1984. $431 \mathrm{p}$.

[26] Silva N. [New methods of microbiological analysis of food, in Portuguese]. Novos métodos de análise microbiológica de alimentos.Coletânea do ITAL. 1996;25(1):1-13.

[27] Silva N, Junqueira VCA, Silveira NFA. [Manual methods of microbiological analysis of food, in Portuguese].Manual de métodos de análise microbiológica de alimentos. São Paulo: Varela; 1997. 259 p.

[28] Banwart GJ. Basic food microbiology. 2nd ed. New York: Van Nostrand Reinhold; 1989. $773 \mathrm{p}$.

[29] Hajdenwurcel JR. [Atlas food microbiology, in Portuguese]. Atlas de microbiologia de alimentos. São Paulo: Fonte Comunicações; 1998. 66 p.

[30] Brazilian Association of Technical Standards. Total coliform bacteria, fecal coliform and Escherichia coli in food: determination of the most probable number (MPN): MB-3463. Rio de Janeiro: ABNT; $1991.7 \mathrm{p}$

[31] Snowdon JÁ, Cliver DO. Microorganisms in honey. International Journal of Food Microbiology. 1996;31:1-26.DOI: 10.1016/0168-1605(96)00970-1. 
[32] Siqueira RS. [Microbiology manual food, in Portuguese].Manual de microbiologia de alimentos. Brasília: EMBRAPA, SPI. Rio de Janeiro: EMBRAPA, CTAA; 1995. 159 p.

[33] International Commission on Microbiological Specifications for Foods (ICMSF). Microorganisms in foods 6: microbial ecology of food commodities. 2nd ed. New York: Kluwer Academic/Plenum; 2005. 764 p.

[34] Pitt JI, Hocking AD. Fungi and Food Spoilage. 2nd ed. North Ryde: Blackie Academic and Professional; 1997. 596 p.

[35] Mothershaw AS, Jaffer T. Antimicrobial activity of foods with different physicochemical characteristics. International Journal of Food Properties. 2004;7:3:629-638.DOI: 10.1080/ 10408398.2013.763765

[36] Ballivián JMP. [Native bees stingless, in Portuguese]. Abelhas nativas sem ferrão. São Leopoldo: Oikos, 2008. 129 p.

[37] Bogdanov S, Jurendic T, Sieber R, Gallman P. Honey for nutrition and health: a review. American Journal of the College of Nutrition. 2008;27:677-689. DOI: 10.1080/07315724. 2008.10719745.

[38] Carvalho CAL, Souza BA, Sodré GS, Marchini LC, Alves RMO. [Bee honey stingless: contribution to the physicochemical characterization, in Portuguese]. Mel de Abelha sem ferrão: contribuição para a caracterização físico-química. Cruz das Almas: Nova Civilização;2005. 32 p.

[39] Mavric E, Wittmann S, Barth G, Henle T. Identification and quantification of methylglyoxal as the dominant antibacterial constituent of manuka (Leptospermum scoparium) honeys from New Zealand. Molecular Nutrition \& Food Research. 2008;52:483-489. DOI: $10.1002 / \mathrm{mnfr} .200700282$.

[40] Barbosa LS, Macedo JL, Silva MRF, Machado A. [Study Mel Quality Biochemist Marketed Bee in the municipality of Caraúbas - RN, in Portuguese]. Estudo Bioquímico de Qualidade do Mel de Abelha Comercializado no Municipio de Caraúbas - RN. Revista Verde. 2014;9(2):45-51.

[41] Molan PC, Russell KM. Non-peroxide antibacterial activity in some New Zealand honeys. Journal of Apicultural Research. 1988;27:62-67.

[42] Bang LM, Buntting C, Molan PC. The effect of dilution on the rate of hydrogen peroxide production in honey and its implications for wound healing. Journal of Alternative and Complementary Medicine. 2003;9:267-273. DOI: 10.1089/10755530360623383.

[43] Clinical and Laboratory Standards Institute. Methods for dilution antimicrobial susceptibility tests for bacteria that grow aerobically; Approved Standard. 9th ed. Wayne: Clinical and Laboratory Standards Institute; 2012. 88 p.

[44] Brazil. Ministry of Agriculture and Supply. Portaria n. 46 of February 10, 1998. Establishes the system of analysis of hazards and critical control points: HACCP to be implemented in the animal products industries [Internet]. 1998. Available from: http://sistemasweb. 
agricultura.gov.br/sislegis/action/detalhaAto.do?method=consultarLegislacaoFederal [Accessed: 2016-08-14].

[45] Silva MBL, ChavesJBP, MessageD, GomesJC, Gonçalves MM, Oliveira GL. [Microbiological quality of honeys produced by small beekeepers and honey warehouses registered with the Federal Inspection Service of the State of Minas Gerais].Qualidade microbiológica de méis produzidos por pequenos apicultores e de méis de entrepostos registrados no Serviço de Inspeção Federal do estado de Minas Gerais. Alimentos e Nutrição. 2008;19(4):417-420.

[46] Sereia MJ, Alves EM, Toledo VAA, Marchini LC, Faquinello P, Sekine ES, Wielewski P. (2011). Microbial flora in organic honey samples of africanized honeybees from Paraná river islands. Food Science and Technology. 2011;31(2):462-466.DOI: 10.1590/ S0101-20612011000200028.

[47] Camargo RCR, Siqueira RJG, Lopes MTR, Pereira FM, Melo AL. [Good Practices in harvesting, extraction and processing of honey, in Portuguese]. Boas Práticas na Colheita, Extracão e Beneficiamento do Mel [Internet]. 2003. Available from: https://www.infoteca.cnptia.embrapa.br/bitstream/doc/66838/1/Doc78.pdf [Accessed: 2016-06-15].

[48] Nakano H, Kizaki H, Sakaguchi G. Multiplication of Clostridium botulinum in dead honeybees and bee pupae, a likley source of heavy contamination of honey. International Journal of Food Microbiology. 1994;21(3):247-252. DOI: 10.1016/0168-1605(94)90031-0.

[49] International Commission on Microbiological Specifications for Foods (ICMSF). [Microorganisms in food 8: use of data for process control assessment and acceptance of the product, in Portuguese] Microrganismos em alimentos 8: utilização de dados para avaliação do controle de processo e aceitação do produto. São Paulo: Bhucher; 2015. 522 p.

[50] Arnon SS, Midura TF, Clay SA, Wood RM, Chin J. Infant botulism. Epidemiological, clinical, and laboratory aspects. Journal American Medical Association, 1977;237(18):1946-1951. DOI:10.1001/jama.1977.03270450036016. 
